\title{
Entrepreneurial Personality: The Role of Narcissism ${ }^{1}$
}

\author{
Cynthia Mathieu \\ Business Department \\ University of Quebec at Trois-Rivières \\ Trois-Rivières, Québec, Canada \\ G9A $5 \mathrm{H} 7$ \\ cynthia.mathieu@uqtr.ca
}

\author{
Étienne St-Jean \\ Ph.D., professeur \\ Institut de recherche sur les PME \\ Université du Québec à Trois-Rivières \\ 3351, boul. des Forges \\ Trois-Rivières (Québec) \\ Canada \\ G9A $5 \mathrm{H} 7$ \\ Tél : 1-819-376-5011 \#4293 \\ etienne.st-jean@uqtr.ca
}

\footnotetext{
${ }^{1}$ Mathieu, C. and É. St-Jean (2013). "Entrepreneurial personality: The role of narcissism.", Personality and Individual Differences, Vol. 55 (5), pp. 527-531 https://doi.org/10.1016/j.paid.2013.04.026
} 


\begin{abstract}
Research has established a number of personality features and behaviours associated with business creation and success. The similarities between these traits and narcissism, a concept with roots in clinical psychology and psychiatry, led the authors to conduct this study, which proposes to measure whether entrepreneurs score higher on a narcissism scale than other vocational groups. The second goal of this study is to measure the role of narcissism on intention to start a business. Student entrepreneurs have been compared with non-entrepreneur students, city workers, and employees and managers from a branch of a large financial institution. Then, students filled out measures of general selfefficacy, locus of control and risk propensity as well as a narcissism scale. Results indicate that student entrepreneurs score significantly higher than all other vocational groups on a measure of narcissism. Results also indicate that narcissism is positively correlated with general self-efficacy, locus of control and risk propensity. Moreover, narcissism plays a significant role in explaining entrepreneurial intentions, even after controlling for selfefficacy, locus of control and risk propensity. Overall, these findings shed new light on the underlying personality traits of entrepreneurs and entrepreneurial intentions and suggest new directions in the study of entrepreneurs' personality profile.
\end{abstract}

Keywords: narcissism, entrepreneurial intentions, self-efficacy, locus of control, risk propensity 


\section{Introduction}

Career choice theory (Holland, 1997) and person-environment fit theory (Judge, \& Kristof-Brown, 2004) stipulate that individuals chose careers and work environments that best fit their values, needs and personality. Narcissistic individuals fantasize about fame and power (Raskin \& Novacek, 1991); see themselves as more intelligent and attractive (Gabriel, Critelli \& Ee, 1994) and are in constant search of admiration and superiority (Morf \& Rhodewalt, 2001). Narcissists are attracted to celebrity (Young \& Pinsky, 2006) and tasks that support their superiority to others in a competitive way (Morf, Weir \& Davidov, 2000). In fact, not surprisingly, narcissists seem to seek out leadership positions in organizations (Campbell \& Campbell, 2009) and what better position for leadership and power than owning a business? It is well recognized that entrepreneurship fosters the myth of generating wealth, among entrepreneurs and in society in general (Shane, 2009). Consequently, entrepreneurship could attract individuals with greater narcissistic personality than other vocational choices. However, to our knowledge, narcissism in entrepreneurs has never been empirically studied.

This study proposes to test whether entrepreneurs are more narcissistic than other vocational groups. Furthermore, our study measures the role of narcissism in explaining entrepreneurial intentions. We think that bridging clinical and personality psychology with entrepreneurial studies may help shed light into the study of "who is the entrepreneur" and better understand the underlying personality construct related to well-studied entrepreneurial personality traits.

\subsection{Entrepreneurs and narcissism}


Entrepreneurs and narcissists share many traits in the Big Five-Factor model (high extraversion and openness to experience, low neuroticism and agreeableness) (Brandstätter, 2011; Paulhus \& Williams, 2002). Of the personality traits that have been most studied in relation to entrepreneurship, we find risk propensity, self-efficacy and locus of control. Results of a meta-analysis on personality traits and entrepreneurial intentions showed that risk propensity yielded the largest effect size (Zhao, Seibert \& Lumpkin, 2010). In their meta-analysis, Stewart and Roth (2001) report that entrepreneurs score significantly higher than managers on risk propensity. Many studies have linked high risk propensity behaviours to narcissism (Foster, Misra \& Reidy, 2009; Lakey, Rose, Campbell \& Goodie, 2008). This could be related to the fact that narcissists are focused on success and achievement, and are not afraid of failure (Elliot \& Thrash, 2001). A study by Foster, Shenesey \& Goff (2009), reports that narcissistic individuals are more prone to risk-taking and differ from non narcissistic individuals in that they perceive greater benefits deriving from risky behaviours. It seems that the display of overconfidence (and perhaps the appeal of power and success) may affect the rational evaluation of risk-taking in narcissistic individuals. Note here that literature has proven that entrepreneurs show higher degrees of overconfidence when compared with managers (Koellinger, Minniti \& Schade, 2007).

Self-efficacy refers to the belief that an individual has it in his or her ability to accomplish specific tasks undertaken (Bandura, 1997). One's perception of self-efficacy does not depend on the number of skills one possesses, but in the belief of what one is able to do with one's own skills in a variety of situations. Individuals who present high generalized self-efficacy have higher hopes of success (Heckhausen \& Schulz, 1995). High levels of generalized self-efficacy have also been associated with business creation 
(Dimov, 2010; Poon, Ainuddin \& Junit, 2006). (Chen, Greene \& Crick 1998) have found that students who manifested entrepreneurial intentions scored higher on a measure of entrepreneurial self-efficacy than students who did not have entrepreneurial intentions. Narcissistic individuals, have inflated views of their abilities (Campbell, Hoffman, Campbell, \& Marchisio, 2011), and think that they are special and unique (APA, 2000) and their primary motive for action is self-enhancement and a sense of entitlement (Campbell, Bonacci, Shelton, Exline \& Bushman, 2004). Furthermore, even when faced with opposing facts, it seems that individuals high on narcissism still consider that they do better than others, and predict that they would do better than others in similar tasks in the future (Campbell, Goodie, \& Foster, 2004).

Internal locus of control (LOC) refers to the belief that one is in control of his own destiny (Rotter, 1966). Because, by definition, entrepreneurs are individuals who chose to "control" their career by creating, and managing their own business, it is not surprising to find that LOC has been vastly studied in relation to entrepreneurial intention (Mueller \& Thomas, 2001). However, results have yielded somewhat conflicting results; while some have found a positive link, others have found no evidence of a link (Chell, 2008). Nevertheless, in a meta-analysis on 20 studies, Rauch and Frese (2005) have found a small but significant difference between business owners and non-owners and a positive correlation between LOC and business success. There is reason to postulate that narcissistic individuals who we hypothesized have high self-efficacy, would also believe that they are in control of their destiny and thus present an elevated internal LOC.

In sum, the overlap between entrepreneurial literature and literature on narcissism leads to the possibility that narcissism could very well be an underlying construct 
explaining entrepreneurship. Consequently, we propose that entrepreneurs are more narcissistic than other vocational groups (Hypothesis 1).

\subsection{The role of narcissism in entrepreneurial intentions}

Entrepreneurial intentions have been associated with entrepreneurial self-efficacy (Chen, Greene \& Crick, 1998; Zhao, Seibert \& Hills, 2005) and risk propensity (Zhao, Seibert \& Lumpkin, 2010). Chen et al. (1998), report that self-efficacy may explain entrepreneurial avoidance in the fact that there may be individuals who avoid starting a business not because they lack necessary skills but because they think they do. On the contrary, if we look at narcissists who tend inflated views of their abilities (Campbell et al., 2011), we could hypothesize that they would think they have the necessary skills to start a business (even though, in reality, they may not). Hence, we suggest that narcissism will influence entrepreneurial intentions (Hypothesis 2).

\section{Material and Methods}

\subsection{Participants and procedure}

Data for this research comes from three separate projects. For the first project, university students have been asked to fill out a survey as part of a larger-scale longitudinal study concerning the choice of the career as an entrepreneur. The survey was conducted online. In total, 1,572 students accepted the invitation, and $89 \%$ of them were enrolled from Universities across Quebec, Canada. From this first wave, 655 students took part in the sixth-month follow-up in which several personality measures were included, such as narcissism. 
To test the first hypothesis, from this second wave, two groups were created. First, we have grouped university students who had been entrepreneurs in the past or who are currently entrepreneurs $(n=108)$. This group will be subsequently called the "entrepreneurial student sample". Secondly, we selected students who had never been entrepreneurs in the past, who are not entrepreneurs now or in the process of starting a business. Out of these, we grouped those who answered "not at all" to the following question: "Do you intend to start a business in the future". Since the survey was geared towards choosing an entrepreneurial career, we wanted to avoid the thematic-biased respondents, and retain only those students who not only had never been an entrepreneur, but also who did not plan to become one in the future. A total of 73 students fit this profile and this sample will be referred to as the "student" sample.

Data for the two other groups come from two studies that are part of a larger investigation on the effects of personality disorders in the workplace.The first group consists of 98 employees and managers from a large Canadian financial institution who completed an online survey during work hours (response rate of $85.3 \%$ ). Data from the second group were collected from 116 white-collar workers and managers working for a public organization (response rate of $91.5 \%$ ). They filled out a paper-pencil survey during work hours.

As can be seen in Table 1, the sex distribution of respondents was comparable between the "city" and "entrepreneurial student" samples, and between the "bank" and "student" samples. However, mean age is different between groups ( $t$ test, $p \leq 0.000$ ), as was expected since we compared student samples and organizational samples. Furthermore, it is not surprising to find a different distribution for levels of education. 
Nevertheless, no significant distribution differences can be found between the "student" and the "entrepreneurial student" samples, or between the "city" and "bank" samples.

Table 1. Descriptive Statistic of the Four Samples

\begin{tabular}{rcccc}
\hline City & Bank & Student & Entrepreneur \\
Women & $52.5 \%$ & $14.3 \%$ & $11.8 \%$ & $52.8 \%$ \\
Mean Age (S.D) & $44.7(8.93)$ & $40.6(12.14)$ & $24.3(4.05)$ & $32.5(10.46)$ \\
High School & $11.4 \%$ & $36 \%$ & $0 \%$ & $0 \%$ \\
College & $58.1 \%$ & $46 \%$ & $0 \%$ & $0 \%$ \\
Undergraduate & $24.8 \%$ & $18 \%$ & $62.3 \%$ & $59.4 \%$ \\
Graduate & $5.7 \%$ & $0 \%$ & $37.7 \%$ & $40.6 \%$ \\
\hline
\end{tabular}

The second wave sample of students will also be used to test the relationship between narcissism and intention to start a business (Hypothesis 2).

\subsection{Measures}

\subsubsection{Narcissism}

Narcissism was measured using a short version of the Narcissistic Personality inventory (NPI-16; Ames, Rose \& Anderson, 2006). Each item presents two statements and the participant must choose the one that best describes him or her. The narcissistic statements were coded 1 whereas the "non-narcissistic" statements were coded 0 , and the 16 items are added together, for a total score ranging from 0 to 16 . All three samples 
showed acceptable level of internal consistency on NPI-16 with Cronbach's Alphas of 0.69 for the student sample; 0.66 for city workers and 0.69 for financial industry employees.

\subsubsection{Intention to start a business}

A modified version of the measure developed by Thompson (2009) was used by adding an item to capture the intention to buy a new business (instead of creating one from the ground up) (seven items). A 7-point Likert scale was used, and items are, for example, "I save money to start a new business", "I don't have plans to start my new business (reversed)", and "I have the intention to start a new business in the future". Cronbach's Alpha for this measure is 0.87 .

\subsubsection{General self-efficacy.}

For the general self-efficacy scale (GSE), we used the measure developed by Schwarzer and Jerusalem (1995), containing ten items and measured using a 7-point Likert scale. Items are, for example, "I can always solve difficult problems if I try hard enough", "It is easy for me to stay concentrated on my goals and achieve them", and "I can remain calm when faced with difficulties because I can rely on my coping skills". Cronbach's Alpha is 0.91 .

\subsubsection{Risk propensity}

We measured risk-taking attitude with the instrument developed by Dohmen et al. (2005). In a scale from $0=$ No willingness to take risks to 10-Complete and full willingness to take risks, respondents note their willingness to take risks in six different situations (driving a car, in your career, in financial decisions, etc.). The last item asks the amount of money, from a hypothetical lottery gain of $100,000 \$$, one is willing to invest in a project 
that has a $50 \%$ chance to double the initial amount and a $50 \%$ chance to lose half of the initial amount (from 0 to 100,000\$, steps of 10,000\$). Cronbach's Alpha for this instrument is 0.76 .

\subsubsection{Locus of control}

We measured the locus of control using the scale developed by Paulhus (1983). Instead of measuring a general locus of control, this author proposed three different spheres of control, namely personal, interpersonal, and socio-political. We used the personal sphere of control (PSC) that consists of 10 items (e.g. Competition discourages excellence; When I get what I want it's usually because I worked hard for it, etc.), with a seven-point Likert scale. Cronbach's Alpha is 0.73 .

We included control measures that can influence the intention to start a business: sex, age, number of children. We also added the ability to obtain funds to start a business (Likert 5) and also how long one can maintain their standard of living without any sources of revenues, both measures to assess wealth of the individual.

Using self-reported data, measuring both predictors and dependent variables may result in common method variance (CMV) (Podsakoff, MacKenzie, Lee, \& Podsakoff, 2003). To reduce possibility of CMV, we first insured confidentiality to each respondent in order to reduce social desirability, respondent leniency, and taking on perceptions consistent with the researchers' objectives (Podsakoff et al., 2003). Also, PSC and Intention to start a business have negative wording and NPI-16 contains binary statements (instead of Likert-type scale), which are two solutions for reducing CMV (Podsakoff et al., 2003). We performed Harman's single factor test as a post hoc test. This procedure involves conducting an unrotated exploratory factor analysis on all of the items collected 
for this study (excluding socio-demographic items). Results indicate that our data converges into 13 factors, and that the first one explains only $18.9 \%$ of the variance. All combined, this strongly suggests that risks of CMV are reduced with our data.

To determine between-group differences (Hypothesis 1), we conducted an ANOVA with post-hoc comparison. Levene's test indicates that the variances are not homogeneous $(p=0.001)$. Consequently, we used the Tamhane's T2 and the Games-Howell tests, which are more restrictive in that situation. To test the relationship between narcissism and intention to start a business (Hypothesis 2), we have conducted hierarchical regression analyses. In the first step, we entered control variables only. Then we tested models with control variables and adding only one variable from entrepreneurial traits (narcissism, GSE, Risk-taking and LOC). Model 6 includes control variables and all trait variables except for narcissism. For the final model, we added narcissism to the previous personality traits and control variables.

\section{Results}

As can be seen in Table 2, differences are significant between all of the nonentrepreneurs' groups and the group composed of entrepreneurial students. There is no significant difference between groups of non-entrepreneurs (City, Bank, and NonEntrepreneur-Students). Clearly, our results show that "entrepreneurial students" score significantly higher on narcissism that other vocational groups, thus supporting Hypothesis 1. Table 3 presents mean, standard deviation and correlation matrix for all variables used in our model. 
Table 2. Differences in the Means on NPI-16 between Samples

\begin{tabular}{rccccc}
\hline & City & Bank & Student & Entrepreneur & $t$ test \\
\hline Mean score & $3.64^{\mathrm{a}}$ & $3.55^{\mathrm{b}}$ & $4.28^{\mathrm{c}}$ & $6.93^{\mathrm{abc}}$ & $p=0.000$ \\
Std. Dev. & 2.56 & 2.53 & 3.05 & 3.33 & \\
Number of cases (n) & 116 & 98 & 73 & 108 & \\
\hline a b and c Significant differencen
\end{tabular}

$\mathrm{a}, \mathrm{b}$ and $\mathrm{c}$ Significant differences in post-hoc tests between groups at $p \leq 0.001$

Furthermore, we have conducted a hierarchical linear regression on the student sample. As we can see in Table 4, Model I shows that being a woman and the number of children are both negatively related to the intention to start a business, but age and ability to obtain funds are positively related. In Model II, we have added the NPI-16, which appeared to be positively significant. In steps 3 to 6 , we have added to our control variables GSE, risk propensity and personal sphere of control. All of these trait variables, when added by themselves to control variables in the model were positively related to intention to start a business. For the seventh step, we have added to the control variables all three entrepreneurial traits (GSE, risk propensity and LOC). All three were positively related to the intention to start a business resulting in an adjusted $R^{2}$ of .252 . Finally, the NPI was added in the seventh model and appears to be positively related to intention to start a business, increasing the adjusted $R^{2}$ to 0.273 . When NPI-16 is added to the model, LOC's contribution became non-significant. For this last model, risk propensity has the highest standardized $\beta$, followed by the NPI-16 and GSE. 
Table 3. Mean, Standard Deviation and Correlation Matrix of Variable Used

\begin{tabular}{|c|c|c|c|c|c|c|c|c|c|c|c|c|}
\hline Variable & Mean & S.D. & 1 & 2 & 3 & 4 & 5 & 6 & 7 & 8 & 9 & 10 \\
\hline $1-\mathrm{Sex}^{\mathrm{a}}$ & 0.52 & 0.50 & 1.0 & & & & & & & & & \\
\hline 2-Age & 24.98 & 6.36 & .04 & 1.0 & & & & & & & & \\
\hline 3-Children & 1.08 & 0.81 & $.08^{*}$ & $.55^{*}$ & 1.0 & & & & & & & \\
\hline 4-Abil. Funds & 3.73 & 1.57 & $-.09 *$ & .04 & $.06^{*}$ & 1.0 & & & & & & \\
\hline 5-Mth wt.Rev & 2.44 & 2.12 & $-.11 *$ & .05 & .01 & $.19^{*}$ & 1.0 & & & & & \\
\hline 6-Intention & 3.35 & 1.35 & $-.27^{*}$ & $.16^{*}$ & -.03 & $.16^{*}$ & $.06^{*}$ & 1.0 & & & & \\
\hline 7-GSE & 5.49 & 0.82 & $-.15 *$ & $.21 *$ & $.15^{*}$ & $.24 *$ & $.10 *$ & $.34 *$ & 1.0 & & & \\
\hline 8-Risk-Taking & 5.77 & 1.54 & $-.35^{*}$ & .07 & .04 & $.14^{*}$ & -.02 & $.39 *$ & $.32 *$ & 1.0 & & \\
\hline 9-PSC & 5.51 & 0.67 & $-.10 *$ & .06 & $.10^{*}$ & $.15^{*}$ & .08 & $.24 *$ & $.45^{*}$ & $.10^{*}$ & 1.0 & \\
\hline 10-NPI & 5.95 & 3.08 & $-.15 *$ & -.01 & .07 & $.10^{*}$ & .05 & $.31 *$ & $.35 *$ & $.30 *$ & $.30 *$ & 1.0 \\
\hline
\end{tabular}

Note: Abil. Funds = Ability to obtain funds; Mth wt. Rev = Months without revenue; GES = General Self-Efficacy; PSC = Personal Sphere of Control; NPI = Narcissistic Personality Inventory.

${ }^{\text {a }}$ Coded Men $=0$, Women $=1$

* Correlation significant at $p \leq 0.05$ 
Table 4. Hierarchical Linear Regression of the Intention to Start a Business

\begin{tabular}{|c|c|c|c|c|c|c|c|}
\hline & $\begin{array}{l}\text { Model I } \\
\text { Std. } \beta\end{array}$ & $\begin{array}{l}\text { Model II } \\
\text { Std. } \beta\end{array}$ & $\begin{array}{c}\text { Model III } \\
\text { Std. } \beta\end{array}$ & $\begin{array}{c}\text { Model IV } \\
\text { Std. } \beta\end{array}$ & $\begin{array}{l}\text { Model V } \\
\text { Std. } \beta\end{array}$ & $\begin{array}{l}\text { Model VI } \\
\text { Std. } \beta\end{array}$ & $\begin{array}{c}\text { Model VII } \\
\text { Std. } \beta\end{array}$ \\
\hline Sex ${ }^{a}$ & $-0.255^{* * *}$ & $-0.238^{* * *}$ & $-0.224^{* * * *}$ & $-0.169^{* * *}$ & $-0.269^{* * *}$ & $-0.132^{* *}$ & $-0.129^{* *}$ \\
\hline Age & $0.225^{* * *}$ & $0.175^{* * *}$ & $0.183^{* * *}$ & $0.132^{* *}$ & $0.151^{* *}$ & $0.106^{*}$ & $0.128^{* *}$ \\
\hline Number of children & $-0.142 * * *$ & -0.024 & $-0.158^{* * *}$ & 0.003 & -0.024 & -0.007 & -0.019 \\
\hline Ability to obtain funds & $0.145^{* * *}$ & 0.065 & $0.091^{* * *}$ & 0.051 & 0.069 & 0.008 & 0.006 \\
\hline Mth without revenues & -0.008 & -0.009 & -0.017 & 0.028 & -0.003 & 0.023 & 0.016 \\
\hline NPI & & $0.311^{* * *}$ & & & & & $0.184^{* * *}$ \\
\hline GSE & & & $0.254^{* * *}$ & & & $0.201^{* * *}$ & $0.159^{* * *}$ \\
\hline Risk-taking & & & & $0.319^{* * *}$ & & $0.266^{* * *}$ & $0.228^{* * *}$ \\
\hline Personal Sphere of Ctrl & & & & & $0.200^{* * *}$ & $0.099^{*}$ & 0.057 \\
\hline Adj. $R^{2}$ & 0.125 & 0.199 & 0.183 & 0.195 & 0.145 & 0.252 & 0.273 \\
\hline $\mathrm{N}$ & 1219 & 509 & 1215 & 514 & 522 & 513 & 508 \\
\hline
\end{tabular}

Note: Abil. Funds = Ability to obtain funds; Mth wt. Rev = Months without revenue; GES = General Self-Efficacy; PSC = Personal Sphere of Control; NPI = Narcissistic Personality Inventory.

${ }^{a}$ Coded Men $=0$, Women $=1$

${ }^{*} p \leq 0.05, * * p \leq 0.01, * * * p \leq 0.001$

\section{Discussion}

This study has found that student entrepreneurs are more narcissistic than students who are non-entrepreneurs, employees and managers from a financial institution and city workers. Since the literature seems to indicate that entrepreneurs and narcissists share personality traits such as risk propensity, and possibly other traits (general self efficacy and locus of control), the fact that entrepreneurs are more narcissistic could explain some of the differences found in the literature between entrepreneurs and managers. 
Results also indicate that high scores on narcissism are positively associated with high scores on GSE, LOC and risk propensity. Since narcissists have a grandiose sense of self-importance (APA, 2000), it is not very surprising to find that narcissists score higher on self-efficacy measures. Self-efficacy has been identified in the literature as one of the main components of intentions to start a business (Chen et al., 1998) and the subsequent start-up (Dimov, 2010). Since all of the three entrepreneurial traits (GSE, LOC and risk propensity) seem to be correlated to narcissism, perhaps working on the underlying personality structure of individuals may help better understand the concept of "the entrepreneurial personality".

Indeed, in terms of predicting intention to start a business, GSE and risk propensity were good predictors. In fact, in the global model, risk propensity was the best predictor of entrepreneurial intentions; this is in line with results from a meta-analysis by Zhao et al. (2010). LOC influenced significantly the intention to start a business, but to a lesser degree. However, when the NPI-16 was added to the model, LOC's contribution became nonsignificant. This finding is in line with previous conflicting results on the role of LOC in entrepreneurial intentions. Judge and Bono (2002) had hypothesized that these conflicting results may be due to the strong resemblance between LOC and GSE. They present the fact that Levenson's GSE measure and Paulhus' LOC measure (both used in the present study) share a common item ("When I make plans, I am certain to make them work"). Since narcissistic individuals seem to show overconfidence in their skills and have a tendency to overclaim their knowledge, perhaps LOC is part of the underlying personality and a resulting trait of a core personality structure captured by the NPI-16. Furthermore, in line with previous research on the subject, in terms of sex, this study has found that 
entrepreneurial intentions are significantly lower for women (Wilson, Kickul \& Marlino, 2007). Moreover, results indicate that being a woman reduces the scores on the NPI-16. This finding corresponds to results found in research on subclinical narcissism indicating that men tend to score higher on the NPI than women (Twenge \& Foster, 2008).

Moreover, when testing our different models including control variables and only one "trait" variable at a time, the model that yielded the strongest results was the one including the NPI-16 (although closely followed with the model including risk propensity). In fact, adding all three traditional trait variables (LOC, risk propensity and GSE) to the model that included only control variables and narcissism, we found that the model was only slightly enhanced. This not only indicates the importance of considering narcissism in predicting entrepreneurial intentions and behaviours but may be an indication that personality traits traditionally related to entrepreneurship could be explained by this underlying personality structure (confounding factor).

\subsection{Limitations and future directions}

To our knowledge, this is the first study to explore the role of narcissism in entrepreneurship. The reliability of the NPI-16, although acceptable was somewhat low. However, Ames et al. (2006) reported that the NPI-16 paralleled the NPI-40 in its relation to other personality measures and dependant variables and found Cronbach Alphas for the NPI-16 similar to the ones found in the present study ranging from 0.65 to 0.72 for their 5 studies. Also, this study relies on student entrepreneurs who may differ from experienced entrepreneurs. Thus, results found in the present study will have to be tested in a population of experienced 
Furthermore, although our results seem to indicate that narcissism is associated with business intentions, whether these results would apply to business success remains to be tested. Just as narcissism was associated with leader emergence but not with leader effectiveness (Campbell et al., 2011), it may also be associated with business start-up but not with business success in the long-run. In other words, we argue that individuals who score very low on a number of narcissistic traits such as risk-taking and overconfidence may never start a business, but those who score very high on the same traits could lead their businesses to a loss.

\section{References}

American Psychiatric Association. (2000). Diagnostic and statistical manual of mental disorders (4th ed., text rev.). Washington, DC: Author.

Ames, D., Rose, P., \& Anderson, C. (2006). The NPI-16 as a short measure of narcissism. Journal of Research in Personality, 40(4), 440-450.

Bandura, A. (1997). Self-efficacy: the exercise of control. New York: W.H. Freeman.

Brandstätter, H. (2011). Personality aspects of entrepreneurship: A look at five metaanalyses. Personality and Individual Differences, 51, 222-230.

Campbell, W. K., Bonacci, A. M., Shelton, J., Exline, J. J., \& Bushman, B. J. (2004). Psychological entitlement: Interpersonal consequences and validation of a new self-report measure. Journal of Personality Assessment, 83, 29-45.

Campbell, W. K., \& Campbell, S. M. (2009). On the self-regulatory dynamics created by the peculiar benefits and costs of narcissism: The case of tragedy of the commons. Self \& Identity, 8, 214-232.

Campbell, W. K., Goodie, A. S., \& Foster, J. D. (2004) Narcissism, confidence and risk attitude. Journal of Behavioral Decision Making, 17, 297-311.

Campbell, W. K., Hoffman, B. J., Campbell, S. M., \& Marchisio, G. (2011). Narcissism in organizational contexts. Human Resource Management Review, 21, 268-284.

Chell, E. (2008). The Entrepreneurial Personality. (2 $2^{\text {nd }}$ ed.). New York (NY): Routledge.

Chen, C. ., Greene, P. G., \& Crick, A. (1998). Does entrepreneurial self-efficacy distinguish entrepreneurs from managers? Journal of Business Venturing, 13, 295-316. 
Dimov, D. (2010). Nascent entrepreneurs and venture emergence: opportunity confidence, human capital, and early planning. Journal of Management Studies, 47 (6), 11231153.

Dohmen, T., Falk, A., Huffman, D., Schupp, J., Sunde, U., \& Wagner, G. (2005). Individual risk attitudes: New evidence from a large, representative, experimentally-validated survey. Bonn, Germany: Institute for the Study of Labor.

Elliot, A. J. \& Thrash, T. M. (2001). Narcissism and motivation. Psychological Inquiry, 12(4), 216-219.

Foster, J. D., Misra, T. A., \& Reidy, D. E. (2009). Narcissists are approach-oriented toward their money and their friends. Journal of Research in Personality, 43 (5), 764769.

Foster, J. D., Shenesey, J. W., \& Goff, J. S. (2009). Why do narcissists take more risks? Testing the roles of perceived risks and benefits of risky behaviors. Personality and Individual Differences, 47 (8), 885-889.

Gabriel, M. T., Critelli, J. W., \& Ee, J. S. (1994). Narcissistic Illusions in Self-Evaluations of Intelligence and Attractiveness. Journal of Personality, 62 (1), 143-155.

Heckhausen, J.,\& Schulz, R. (1995). A life-span theory of control. Psychological Review, 102, 284-304.

Holland, J. L. (1997). Making Vocational Choices. Odessa, FL: Psychological Assessment Resources.

Judge, T. A., \& Bono, J. E. (2002). Are self-esteem, generalized self-efficacy, neuroticism, and locus of control indicators of a common construct? In B. W. Roberts \& R. Hogan (Eds.). Personality Psychology in the Workplace. Washington, DC:American Psychological Association, pp. 93-118.

Judge, T. A., \& Kristof-Brown, A. (2004). Personality, interaction psychology, and personorganization fit. In B. Schneider \& D. B. Smith (Eds.), Personality and organizations. Mahwah, NJ: Erlbaum, pp. 87-109.

Koellinger, P., Minniti, M., \& Schade, C. (2007). "I think I can, I think I can": Overconfidence and entrepreneurial behavior. Journal of Economic Psychology, 28 (4), 502-527.

Lakey, C. E., Rose, P., Campbell, W. K., \& Goodie, A. S. (2008). Probing the link between narcissism and gambling: the mediating role of judgment and decision-making biases. Journal of Behavioral Decision Making, 21 (2), 113-137.

Morf, C. C., \& Rhodewalt, F. (2001). Unraveling the Paradoxes of Narcissism: A Dynamic Self-Regulatory Processing Model. Psychological Inquiry, 12 (4), 177-196.

Morf, C. C., Weir, C., \& Davidov, M. (2000). Narcissism and Intrinsic Motivation: The Role of Goal Congruence. Journal of Experimental Social Psychology, 36 (4), 424-438. 
Mueller, S. L. \& Thomas, A. S. (2001). Culture and entrepreneurial potential: A nine country study of locus of control and innovativeness. Journal of Business Venturing, 16 (1), 51-75.

Paulhus, D. (1983). Sphere-specific measures of perceived control. Journal of Personality and Social Psychology, 44(6), 1253-1265.

Paulhus, D.L., \& Williams, K.M. (2002). The dark triad of personality: Narcissism, Machiavellianism, and psychopathy. Journal of Research in Personality, 36, 556563.

Podsakoff, P. M., MacKenzie, S. B., Lee, J. Y., \& Podsakoff, N. P. (2003). Common method biases in behavioral research: A critical review of the literature and recommended remedies. Journal of Applied Psychology, 88(5), 879-903.

Poon, J. M. L., Ainuddin, R. A., \& Junit, S. O. H. (2006). Effects of self-concept traits and entrepreneurial orientation on firm performance. International Small Business Journal, 24 (1), 61-82.

Raskin, R. N. \& Novacek, J. (1991). Narcissism and the use of fantasy. Journal of Clinical Psychology, 47 (4), 490-499.

Rauch, A., \& Frese, M. (2005). Let's put the person back into entrepreneurship research: A meta-analysis on the relationship between business owners' personality traits, business creation, and success. European Journal of Work and Organizational Psychology, 16 (4), 353-385.

Rotter, J. B. (1966). Generalized expectancies for internal versus external control of reinforcement. Psychological Monographs, 80 (1), 1-28.

Schwarzer, R. \& Jerusalem, M. (1995). Generalized self-efficacy scale. In J. Weinman \& S. Wright \& M. Johnston (Eds.), Measures in health psychology: A user's portfolio. Causal and control beliefs, pp. 35-37. Windsor, England: NFERNELSON.

Shane, S. (2009). Why encouraging more people to become entrepreneurs is bad public policy. Small Business Economics, 33(2), 141-149.

Stewart Jr., W. H., \& Roth, P. L. (2001). Risk propensity differences between entrepreneurs and managers: A meta-analytic review. Journal of Applied Psychology, 86 (1), $145-153$.

Thompson, E. (2009). Individual entrepreneurial intent: construct clarification and development of an internationally reliable metric. Entrepreneurship Theory and Practice, 33 (3), 669-694.

Twenge, J. M., \& Foster J. D. (2008). Mapping the scale of the narcissism epidemic: Increases in narcissism 2002-2007 within ethnic groups. Journal of Research in Personality, 42(6), 1619-1622.

Wilson, F., Kickul, J. R., \& Marlino, D. (2007). Gender, Entrepreneurial Self-Efficacy, and Entrepreneurial Career Intentions: Implications for Entrepreneurship Education. Entrepreneurship Theory and Practice, 31 (3), 387-407. 
Young, S. M., \& Pinsky, D. (2006). Narcissism and celebrity. Journal of Research in Personality 40, 463-471.

Zhao, H., Seibert, S. E., \& Hills, G. E. (2005). The Mediating Role of Self-Efficacy in the Development of Entrepreneurial Intentions. Journal of Applied Psychology, 90 (6), 1265-1272.

Zhao, H., Seibert, S. E., \& Lumpkin, G. T. (2010). The relationship of personality to entrepreneurial intentions and performance: A meta-analytic review. Journal of Management, 36 (2), 381-404. 